\title{
Electrochemical actuation of nickel hydroxide/oxyhydroxide at sub-volt voltages
}

Kin-Wa Kwan, Nga-Yu Hau, Shien-Ping Feng and Alfonso Hing-Wan Ngan*

Department of Mechanical Engineering, The University of Hong Kong

Pokfulam Road, Hong Kong, China

*Corresponding author, email: hwngan@hku.hk 


\section{Abstract}

The development of materials capable of actuating at low triggering voltages is crucial for applications such as compact prime movers for soft, micro robots. In this paper, the electrochemical actuation of $\mathrm{Ni}(\mathrm{OH})_{2} / \mathrm{NiOOH}$ in alkaline environment at low voltages is demonstrated and studied for the first time. Specifically, sub-micron layers of $\mathrm{Ni}(\mathrm{OH})_{2} / \mathrm{NiOOH}$ deposited on $\mathrm{Ni}$ films a few microns thick by anodic electrodeposition were found to undergo reversible contraction by $\sim 0.1 \%$ in an alkaline solution under a low voltage of only $\sim 0.4 \mathrm{~V}$, causing a 5-mm long bi-layer actuator to bend by $\sim 3.5 \mathrm{~mm}$ at its end, giving a large device strain of $\sim 70 \%$. The actuation mechanism is found to be due to a redox reaction in the $\mathrm{Ni}(\mathrm{OH})_{2} / \mathrm{NiOOH}$ couple. By masked electrodeposition, successful fabrication of actuators of various shapes and actuation performance was also demonstrated. The required electrolyte can be packaged with the actuating material to achieve a stand-alone actuating device.

Keywords: Electrochemical actuators, low voltages, anodic electrodeposition, nickel hydroxide/oxyhydroxides, artificial muscles, soft robotics

\section{Introduction}

The last two decades have seen a surge in interest on developing small, compact and self-contained actuating materials for applications as artificial muscles, to replace bulky pneumatic or hydraulic actuators, motors or engines, for robotics [1]. Conventional piezoelectric ceramics actuate with large rate response of $>10 \% / \mathrm{s}$ and good strains of $\sim 0.1 \%$ which is already close to the elastic limit of the material, but they do so only under high triggering voltages typically in the $\mathrm{kV}$ range [2-4]. Dielectric elastomers also show similar rate response and even much larger actuating strains, but again, they typically require $\mathrm{kV}$ voltages to actuate [5-9]. The kilo-volt requirements of these materials make them unsuitable for compact designs, as in microrobots. Of other known types of actuating materials, a few can actuate at low voltages in the 1 to $10 \mathrm{~V}$ range. 
Conducting polymers can actuate from less than a volt to a few volts giving good strains of a few \%, but their rate response is slow due to the reliance on ion diffusion within the polymer to cause actuation [1013]. Carbon nanotubes can also actuate at a few volts, with both good strain and rate responses [14-17]. Nanoporous noble metals such as Au and Pt are known to actuate in electrolytic environments under low voltages by changes in surface stress associated with the electrical double layer (EDL) at the electrolytemetal interface [18-22]. On the other hand, nanoporous $\mathrm{Ni}$, as a non-noble metal much cheaper than noble counterparts, has also been found to exhibit electrochemical actuation [23-26]. Cyclic voltammetry and electrical impedance spectroscopy indicated that a redox couple on the Ni surfaces is responsible for the electrochemical actuation [24-26], and $\mathrm{Ni}(\mathrm{OH})_{2} / \mathrm{NiOOH}$ was suggested as such a possible redox couple [24-26], although no concrete proof has been obtained so far.

The redox couple $\mathrm{Ni}(\mathrm{OH})_{2} \leftrightarrow \mathrm{NiOOH}$ is a well-known material system for use as electrodes in nickel-metal hydride rechargeable batteries, in addition to other usages including catalysts and sensors [27]. While the redox reaction in Ni hydride rechargeable batteries during charging and discharging can cause mechanical swelling and shrinkage in the electrode which will limit the life of the battery [28-31], in the present work, we explore a promising use of such electrochemomechanical effects as electrochemical actuators. Specifically, the unit cell volume of $\mathrm{Ni}(\mathrm{OH})_{2}$ can decrease by more than $10 \%$ when oxidized into $\mathrm{NiOOH}$ [32], and reversible redox zipping between the two phases $\mathrm{Ni}(\mathrm{OH})_{2}$ and $\mathrm{NiOOH}$ is known to happen within low voltage ranges of less than one volt $[33,34]$. Such remarkable properties should make $\mathrm{Ni}(\mathrm{OH})_{2} / \mathrm{NiOOH}$ a promising material system for electrochemical actuation under low triggering voltages. In this work, we successfully demonstrate that $\mathrm{Ni}(\mathrm{OH})_{2} / \mathrm{NiOOH}$ directly fabricated by anodic electrodeposition on Ni films can undergo highly reversible and stable electrochemical actuation under low voltages of only $\sim 0.4 \mathrm{~V}$ in an alkaline medium, with the intrinsic actuation strain higher than $0.1 \%$. Through proper device engineering, we also demonstrate that high device strains approaching unity can be produced from the intrinsic actuation strain of such a material system. Furthermore, by applying masked electrodeposition in the fabrication, $\mathrm{Ni}(\mathrm{OH})_{2} / \mathrm{NiOOH}$ actuators of various shapes can be built. These show 
that $\mathrm{Ni}(\mathrm{OH})_{2} / \mathrm{NiOOH}$ is a promising and versatile material system for developing artificial muscles for soft or micro robots.

\section{Experimental}

\subsection{Fabrication of the Actuators}

$\mathrm{Ni}(\mathrm{OH})_{2} / \mathrm{NiOOH}$ was deposited on thin films of Ni metal the fabrication of which is first described here. The Ni films were plated on fluorine doped tin oxide (FTO) glass by a Ni Plating Kit (Caswell) using a CHI 660E (CH Instruments) electrochemical workstation. To make actuators of a cantilever shape, a mask of $50 \mu \mathrm{m}$-thick chemical-resist sticker (Max Bepop, CM-200E) with rectangular cuts of $1 \mathrm{~mm} \times 15 \mathrm{~mm}$ was first adhered to the FTO. The plating bath was a 3-electrode electrolytic cell using a Pt mesh counter electrode. Voltages of $-1.2 \mathrm{~V}$ vs SCE for various durations ranging from $3.75 \mathrm{~min}$ to $12.5 \mathrm{~min}$ were applied to obtain different Ni thickness $t_{N i}$. After rinsing by DI water, rectangular Ni films with a smooth and shiny surface were obtained.

For the electrodeposition of $\mathrm{Ni}(\mathrm{OH})_{2} / \mathrm{NiOOH}$, lacquer was first painted on the $\mathrm{Ni}$ films (still supported by FTO) so that only $1 \mathrm{~mm} \times 5 \mathrm{~mm}$ areas would be plated with $\mathrm{Ni}(\mathrm{OH})_{2} / \mathrm{NiOOH}$. The same 3 electrode plating bath and electrochemical workstation were used, with the solution changed into $0.13 \mathrm{M}$ $\mathrm{NiSO}_{4}, 0.1 \mathrm{M} \mathrm{NaOAc}$ and $0.13 \mathrm{M}$ of $\mathrm{Na}_{2} \mathrm{SO}_{4}$. The plating anodic current density used was mainly 0.4 $\mathrm{mA} / \mathrm{cm}^{2}$ for 30 min under vigorous stirring. A uniform black or dark brown layer, which was subsequently characterized to be $\mathrm{Ni}(\mathrm{OH})_{2} / \mathrm{NiOOH}$, was observed. Other current densities (from 0.04 to $1 \mathrm{~mA} / \mathrm{cm}^{2}$ ) and plating durations (from 5 to $50 \mathrm{~min}$ ) were also studied. After rinsing and detaching the lacquer and mask by tweezers, the rectangular bilayers comprising $\mathrm{Ni}(\mathrm{OH})_{2} / \mathrm{NiOOH}$ on top of $\mathrm{Ni}$ films were carefully peeled off from the FTO. The uncoated region of $\mathrm{Ni}$ was attached to $\mathrm{Cu}$ tape $\left(3 \mathrm{M}^{\mathrm{TM}}\right)$ to form the cantileveractuators as shown in the inset of Fig. 1a. For each plating parameter, 5 samples were made and each was tested for 10 cycles under cyclic voltammetry, giving 50 measurements for the end-deflection data. The 
data points in Fig. 3 are obtained from the mean of the end-deflection normalized with the length of the actuator, with the error bars indicating the standard deviations.

\subsection{Actuation Tests}

The actuation tests were carried out in a 3-electrode cell (Fig. 1a). In each test, a cantilever-actuator was held vertically as shown. Voltage was applied to the actuator by an electrochemical workstation (LK2006A, Lanlike) under $1 \mathrm{M} \mathrm{NaOH}$ against SCE reference electrode. The end-deflection of the cantilever-actuators was video-recorded by a compact digital camera (DSC-H70, Sony Co.). For some actuators with smaller end deflections, an optical microscope (Olympus Co.) was used. A CCD camera (DXC-107P, Sony Co.) was connected to the microscope via a microscope attachment (WV-9005, Matsushita Comm. Industrial Co. Ltd). The captured videos were processed by a computer freeware Kinovea to obtain the numerical data for the end-deflection measurement. Figure 1b,c show the schematic diagram and photographs of an actuator undergoing reduction and oxidization during the test.

\subsection{Characterization of the Actuators}

The thickness of the Ni substrate was measured by a DektakXT® stylus profiler (Bruker). Microstructural characterization was carried out by scanning electron microscopy (SEM), transmission electron microscopy (TEM), X-ray photoelectron spectroscopy (XPS) and X-ray diffraction (XRD). A Leo 1530 FEG SEM and a Hitachi S4800 FEG SEM were used to image the surface morphologies and thickness of the $\mathrm{Ni}(\mathrm{OH})_{2} / \mathrm{NiOOH}$. TEM imaging and selected area electron diffraction (SAED) were performed by a JEOL 2010 TEM. The TEM samples were prepared by oxidizing or reducing the electrodeposited $\mathrm{Ni}(\mathrm{OH})_{2} / \mathrm{NiOOH}$ in $1 \mathrm{M} \mathrm{NaOH}$ for $30 \mathrm{~min}$ at $0.4 / 0 \mathrm{~V}$ vs $\mathrm{SCE}$. Then, the $\mathrm{Ni}(\mathrm{OH})_{2} / \mathrm{NiOOH}$ layer was scratched off from the Ni substrate and adhered onto a formvar film. 
XPS was performed in a Kratos Axis Ultra Spectrometer using a monochromatic Al Ka source. Glazing incidence XRD was performed in a Rigaku Smartlab diffractometer with an incidence angle of $0.5^{\circ}$ using a monochromatic $\mathrm{Cu} \mathrm{K} \alpha$ source $(\lambda=1.5406 \AA)$. In addition to the oxidized/reduced $\mathrm{Ni}(\mathrm{OH})_{2} / \mathrm{NiOOH}$ samples described above, a bare Ni sample prepared by the first electrodeposition step was also characterized for comparison purposes.

\section{Results}

\subsection{Actuation behavior}

Bilayered cantilevers comprising a thin layer of the $\mathrm{Ni}(\mathrm{OH})_{2} / \mathrm{NiOOH}$ actuating material backed by a passive Ni layer were fabricated as described in the Experimental section. On applying a positive potential to the cantilever actuators in $1 \mathrm{M} \mathrm{NaOH}$ solution as shown in Fig. 1a, they exhibit large bending towards the side of the $\mathrm{Ni}(\mathrm{OH})_{2} / \mathrm{NiOOH}$ layer, corresponding to contractive actuation of the latter (Fig. 1b,c). The actuation is reversible during potential cycling, as shown in the example in Supplementary Movie 1. Accompanying the actuation, the color of the $\mathrm{Ni}(\mathrm{OH})_{2} / \mathrm{NiOOH}$ layer also turned slightly darker upon oxidation (increasing) and paler upon reduction (decreasing potential), as shown in Supplementary Movie 2 - the color change here is a good indication of an electrochemical reaction. The end-deflection per unit length of the cantilever-actuator $(D / L)$, used here as a measure of the device strain of the cantilever-actuator, was measured under cyclic potential scanning from 0 to $0.425 \mathrm{~V}$ vs SCE at a rate of $25 \mathrm{mV} / \mathrm{s}$. The results are plotted against the applied voltage for different Ni film thickness $t_{N i}$ in Fig. 2a. The actuation was faster for smaller $t_{N i}$, with the highest $D / L$ reaching $\sim 0.7$ for the smallest $t_{N i}=1.3 \mu \mathrm{m}$ studied. The hysteresis in the response is likely caused by time-dependent factors including kinetic, mass-transfer and ohmic resistances, as quasi-reversibility is observed from the cyclic voltammetry, where the ratio of peak currents for oxidation to reduction is smaller than 1 and the difference in the peak potentials is larger than $59 \mathrm{mV}$ 
[35]. Also, redox reaction of $\mathrm{Ni}(\mathrm{OH})_{2} / \mathrm{NiOOH}$ was shown to exhibit time-independent hysteresis, which is thought to be caused by the ion intercalation or phase separation during the reaction [36].

The cyclic voltammetry $(\mathrm{CV})$ in Fig. $2 \mathrm{~b}$ indicates clearly a redox reaction with an oxidation peak at $\sim 0.37 \mathrm{~V}$ and a reduction peak at $\sim 0.25 \mathrm{~V}$, which are broadly similar to other $\mathrm{CV}$ reported for the redox couple $\mathrm{Ni}(\mathrm{OH})_{2} / \mathrm{NiOOH}$ in the literature $[34,37]$. The charge transfer to the actuator from the workstation was calculated by integrating current over time, and as shown in Fig. 2c, the rise and fall of the charge transferred, which corresponds to the progression of the oxidation reaction (i.e. amount of oxidant formed) according to the Faradaic law, coincide with the rise and fall of $D / L$, indicating that the actuation was mainly caused by the redox reaction, as a result of the volume decrease on oxidation. Figure $2 \mathrm{~d}$ shows the $D / L$ and the voltage applied over 10 typical cycles for the $1.3 \mu \mathrm{m} t_{N i}$ actuator. Fig. S2 in the Supplementary Information shows the last 36 cycles of a 100 -cycle test under 0.2 to $0.36 \mathrm{~V}$ vs SCE voltage cycling at 25 $\mathrm{mV} / \mathrm{s}$, for a $1.3 \mu \mathrm{m} t_{N i}$ cantilever-actuator which had been tested for 400 cycles in prior. The $D / L$ is very steady, indicating the high stability of the system.

Figure 3a shows the measured device strain $\mathrm{D} / \mathrm{L}$ in $1 \mathrm{M} \mathrm{NaOH}$ of cantilever-actuators with different Ni thicknesses $t_{N i}$, all with their $\mathrm{Ni}(\mathrm{OH})_{2} / \mathrm{NiOOH}$ layers deposited at $0.4 \mathrm{~mA} / \mathrm{cm}^{2}$ for $30 \mathrm{~min}$. It can be seen that the device strain decreases as the Ni layer becomes thicker, which is not surprising since a thicker Ni layer would impose higher rigidity constraint opposing the actuation of the $\mathrm{Ni}(\mathrm{OH})_{2} / \mathrm{NiOOH}$ layer. When the actuating layer is thin compared to the Ni supporting layer, the device strain is given by the Hsueh model as

$$
\frac{D}{L} \approx 3 \varepsilon_{o x}\left(\frac{E_{a}}{E_{N i}}\right) \frac{L t_{a}}{t_{N i}^{2}}
$$

where $\varepsilon_{o x}$ is the oxidation actuation strain of the $\mathrm{Ni}(\mathrm{OH})_{2} / \mathrm{NiOOH}$ layer, $E_{a, N i}$ is the Young modulus of the deposited $\mathrm{Ni}(\mathrm{OH})_{2} / \mathrm{NiOOH}$ or $\mathrm{Ni}$ layer and $t_{a, N i}$ is their thickness (see Supplementary Information for details). The inset in Fig. 3a shows that the measured device strain $D / L$ obeys an inverse relation with $t_{N i}^{2}$ according to equation (1), and the $\varepsilon_{o x}$ obtained from the slope is $0.16 \pm 0.01 \%$. 
Figure $3 b, c$ show the effects of the plating time and current density on the thickness of the $\mathrm{Ni}(\mathrm{OH})_{2} / \mathrm{NiOOH}$ layer and the device strain $\mathrm{D} / \mathrm{L}$. It can be seen that the $\mathrm{Ni}(\mathrm{OH})_{2} / \mathrm{NiOOH}$ thickness increases with plating time. The same also applies to the increasing plating current density except at the highest value of $1 \mathrm{~mA} / \mathrm{cm}^{2}$, at which significant bubble formation occurred on the plating surface. The results show that the device strain $\mathrm{D} / \mathrm{L}$ generally increases with the $\mathrm{Ni}(\mathrm{OH})_{2} / \mathrm{NiOOH}$ thickness, in accordance with equation (1). The device strain $D / L$ exhibits large scatter at the plating time of $50 \mathrm{~min}$, at which holes formed on the samples, possibly due to the partial dissolution of Ni by the anodic current during the prolonged electrodeposition. Therefore, there is a limiting plating time (40 min) and plating current density $\left(0.6 \mathrm{~mA} / \mathrm{cm}^{2}\right)$ for the electrodeposition of $\mathrm{Ni}(\mathrm{OH})_{2} / \mathrm{NiOOH}$.

With the present bilayered cantilever-actuators behaving as a type of prime mover, a relevant property to consider would be their load-displacement characteristics. For a skin-effect actuator of a cantilever shape, the load is more conveniently represented by an applied moment $M$, as shown in Fig. S3 in the Supplementary Information. To determine the moment vs deflection characteristics of the present cantilever-actuator, one way would be to use a tester to apply different values of moment load $M$ to the actuator and see its response. However, a bending-moment tester is not easy to build, and so the moment vs deflection characteristics are considered theoretically in Supplementary Information. A linear relation is found for the bending-moment load vs $D / L$, giving a parabolic relation between the external work density and $D / L$. Therefore, the maximum work density is exerted at halved the maximum device strain.

\subsection{Self-contained Actuating Assembly}

The bilayered cantilever-actuators described so far requires an alkaline electrolyte environment to operate and this may pose a limitation on application. However, the required liquid phase electrolyte can be packaged into an assembly of the actuating material to achieve a stand-alone device that can actuate in dry ambient conditions. One possible design is shown in Figure 3d. Here, a thin liquid film of the $1 \mathrm{M} \mathrm{NaOH}$ 
electrolyte was sandwiched between two bilayered cantilever-actuators of the type shown in Figure $1 b, c$; the liquid film was held in place simply by surface-tension effects. The two cantilevercantilevers were connected to the electrodes of the electrochemical workstation as shown in Figure 3d. In this design, the $\mathrm{Ni}(\mathrm{OH}) 2 / \mathrm{NiOOH}$ actuating layers of the two cantilever-actuators are exposed to the electrolyte film and facing each other, so that as an a.c. signal is applied by the electrochemical workstation, the two cantilever-actuators would take turn to actuate on half cycles of the applied voltage, resulting in oscillatory bending of the device. Snapshots of the actual operation of the device assembly in air under a voltage scan rate of $1 \mathrm{~V} / \mathrm{s}$ from $-2 \mathrm{~V}$ to $2 \mathrm{~V}$ are shown in Figure $3 \mathrm{~d}$ together with the corresponding cyclic voltammogram (CV), and Supplementary Movie 3 shows the entire process. Bending of the device can be seen to occur in synchrony with the oxidation peaks in the CV under both directions. The device can actually actuate rather fast under larger voltage scan rates - Supplementary Movies 4, 5 and 6 show the operation of the device under 10V/s, 50/s and 100V/s, respectively, where large actuation amplitudes were still achieved.

\subsection{Microstructure of the actuating layer}

Figure 4a,b show that the electrodeposited $\mathrm{Ni}(\mathrm{OH})_{2} / \mathrm{NiOOH}$ was in the form of uniform solid layers, and this is due to the vigorous stirring of the electrolyte during the deposition process. This is important for the actuation, since equation (1) indicates that for the same intrinsic actuation strain $\varepsilon_{o x}$, a larger device strain $D / L$ can be obtained by a larger $E_{a}$ of the actuation layer. Previous attempts to electrodeposit $\mathrm{Ni}(\mathrm{OH})_{2} / \mathrm{NiOOH}$ using similar electrolyte and voltage-current conditions, but without stirring of the electrolyte, produced nanoporous structures of the material [38], and this is confirmed in the present work as discussed in the Supplementary Information. A nanoporous structure would have a lower Young's modulus than a solid layer of the same material, and according to equation (1), the actuation performance of the device will be hampered. 
Figure $4 \mathrm{c}$ shows dark-field (DF) TEM images of the reduced and oxidized actuation material taken using portions of the lower-order diffraction rings in the diffraction patterns as indicated in Figure $4 \mathrm{~d}$. The larger bright spots indicated by red arrows are therefore nano-crystals, and it can be seen that the oxidized sample contained larger crystals than the reduced sample. The corresponding selected area electron diffraction (SAED) patterns are shown in Fig. 4d. Broad diffraction rings are seen in the SAED implying limited crystallinity. Comparing the oxidized and reduced states, the radii of the diffraction rings are about the same, although the smallest ring observed in the oxidized sample is not found in the reduced sample. Also, their relative intensities appear to be different, which agrees with the difference in crystallinity as observed in the DF images. The inter-planar spacing measured from the ring radii cannot be matched with a single structure among the known phases of $\mathrm{Ni}(\mathrm{OH})_{2}, \mathrm{NiOOH}$ and $\mathrm{NiO}$, as shown in Table 1.

The XPS spectrum in Fig. 5a confirms that the first electrodeposited layer was $\mathrm{Ni}$, and the characteristic peaks of $\mathrm{Ni} 2 \mathrm{p}$ spectrum of $\mathrm{Ni}(\mathrm{OH})_{2}$ at 860.9 and $855.6 \mathrm{eV}$ [39] are found in the electrodeposited $\mathrm{Ni}(\mathrm{OH})_{2} / \mathrm{NiOOH}$ layer both after being oxidized and reduced. These peaks are slightly shifted from those of $\mathrm{Ni}(858.4$ and $852.6 \mathrm{eV})$. The $\mathrm{O} 1 \mathrm{~s}$ peak at $531.2 \mathrm{eV}$ corresponds to $\mathrm{OH}^{-}\left(\mathrm{Fig}^{2}\right.$. $\left.5 \mathrm{~b}\right)$, and the oxidized sample has an extra hump at around $529 \mathrm{eV}$, which may correspond to $\gamma$ - $\mathrm{NiOOH}$ or $\mathrm{NiO}$ $[40]$.

From the XRD results in Fig. 5c, sharp peaks for Ni (111), (200) and (220) planes are observed at $2 \theta=44.7^{\circ}, 52.0^{\circ}$ and $76.7^{\circ}$, again showing that the first electrodeposited layer was Ni. The curves for both oxidized and reduced $\mathrm{Ni}(\mathrm{OH})_{2} / \mathrm{NiOOH}$ show extra peaks compared to that of $\mathrm{Ni}$ (Fig. $5 \mathrm{~d}$ shows enlarged views of the last peaks). The $2 \theta$ of the peak position for the oxidized sample are $18.0^{\circ}, 38.4^{\circ}$ and $67.2^{\circ}$, and $16.5^{\circ}, 35.0^{\circ}$ and $60.9^{\circ}$ for the reduced sample. The corresponding inter-planar spacing is given in Table 1 .

From the cyclic actuation tests, the CV in Fig. $2 \mathrm{~b}$ and the charge against voltage in Fig. 2c show that the actuation was caused by a redox reaction. The peak potentials match those of the $\mathrm{Ni}(\mathrm{OH})_{2} \leftrightarrow$ $\mathrm{NiOOH}$ redox reaction [34]. However, as is shown in the inset in Fig. 2b, a small hump appeared on the oxidation peak, suggesting two phases in the actuating layer undergoing the oxidation reaction. The main 
peak is likely associated with the oxidation of $\alpha-\mathrm{Ni}(\mathrm{OH})_{2}$, while the hump on slightly higher potential suggests the oxidation of $\beta-\mathrm{Ni}(\mathrm{OH})_{2}$. In Fig. S4 of the Supplementary Information, the structure electrodeposited by an unstirred plating bath was shown to be nanoporous, as is similar to Chang [38]. The $\mathrm{CV}$ of this structure under $1 \mathrm{M} \mathrm{NaOH}$ clearly shows two peaks, which are possibly the redox peaks for the $\alpha \leftrightarrow \gamma$ and $\beta \leftrightarrow \beta$ phase of $\mathrm{Ni}(\mathrm{OH})_{2} \leftrightarrow \mathrm{NiOOH}$ [41]. This suggests that the redox reactions involved $\alpha / \beta$ $\mathrm{Ni}(\mathrm{OH})_{2}$ and $\gamma / \beta-\mathrm{NiOOH}$ in the $\mathrm{Ni}(\mathrm{OH})_{2} / \mathrm{NiOOH}$ layer. (It is noted that at the same plating current density and time, the actuation of the nanoporous structure was smaller than the solid counterpart, showing that the structure density plays an important role in the actuation as discussed earlier.) Also, the color change observed in the actuation tests agrees with the known electrochromic properties of $\mathrm{Ni}(\mathrm{OH})_{2} / \mathrm{NiOOH}[42]$. The color change was less significant in the solid structure; however, an almost reversible change in color can be observed in the nanoporous structure.

Given that in Table 1, the inter-planar spacing measured from SAED and XRD cannot be matched with a single structure of $\mathrm{Ni}$ oxide, hydroxides or oxyhydroxides from the literature, the deposition may be a mixture of $\mathrm{NiO}, \alpha / \beta-\mathrm{Ni}(\mathrm{OH})_{2}$ and $\alpha / \gamma-\mathrm{NiOOH}$. The SAED resembles that of a turbostratic structure with short- or intermediate-range order [43]. The first peak for the XRD of the reduced sample could be $\alpha$ - or $\beta-\mathrm{Ni}(\mathrm{OH})_{2}$; the (100) inter-planar spacing of the former is $4.62 \AA$ and the (001) of the latter is $4.61 \AA$ [27]. The higher measured spacing might be caused by the high degree of hydration that leads to a stacking fault disorder [44, 45]. Furthermore, from the weak and broad peaks in the XRD (Fig. 5c,d), the structure of the $\mathrm{Ni}(\mathrm{OH})_{2} / \mathrm{NiOOH}$ is poorly crystallized [46], which agrees with the SAED results. Therefore, the present $\mathrm{Ni}(\mathrm{OH})_{2} / \mathrm{NiOOH}$ layer may contain turbostratic $\alpha-\mathrm{Ni}(\mathrm{OH})_{2}[34]$ and disordered hydroxides/oxyhydroxides. From the $2 \theta$-position of the peaks in the XRD results, the inter-planar spacing of the oxidized sample is $8 \%$ smaller than that of the reduced sample. The percentage change is comparable with the known reduction of $10 \%$ and $12 \%$ respectively in the lattice constants $a$ and $c$ for the oxidation $\alpha-\mathrm{Ni}(\mathrm{OH})_{2} \rightarrow \gamma-\mathrm{NiOOH}$. For $\beta-\mathrm{Ni}(\mathrm{OH})_{2} \rightarrow \beta-\mathrm{NiOOH}$; the lattice constant $a$ decreases by $10 \%$ while $c$ increases by $4 \%[32,47]$. The contraction of electrodeposited $\alpha-\mathrm{Ni}(\mathrm{OH})_{2} \rightarrow \gamma-\mathrm{NiOOH}$ had been measured by atomic force microscopy 
$[48,49]$, which agrees in the order of magnitude with the present results. Thus, all in all, it is convincing enough to conclude that the actuating mechanism is the redox reaction: $\mathrm{Ni}(\mathrm{OH})_{2} \leftrightarrow \mathrm{NiOOH}$.

\section{Discussion}

The intrinsic actuating strain of $\sim 0.16 \%$ of the present $\mathrm{Ni}(\mathrm{OH})_{2} / \mathrm{NiOOH}$ is comparable to some of the nanoporous metals, but is lower than the best nanoporous metals [22] or electroactive polymers [1]. The main advantage of the present material, however, is the low voltage of $\sim 0.4 \mathrm{~V}$ required to trigger the actuation. The intrinsic actuation strain in fact does not matter, as it is also shown here that an intrinsic strain of $\sim 0.16 \%$ can be engineered to give a large device strain of $\sim 70 \%$, by a bilayered design of the cantilever actuators. As indicated by equation (1), such a large device strain is accomplished by a large $L / t_{N i}$ ratio of $\sim 3800$ in the present study, in addition to using vigorous electrolyte stirring to achieve a solid actuation layer with a higher $E_{a}$ as discussed above. A further advantage of the present actuating material is that it can be fabricated easily into different ratios of thickness and various shapes. As the thickness of $\mathrm{Ni}(\mathrm{OH})_{2} / \mathrm{NiOOH}$ is linearly related to the plating time and plating current density (Fig. 3), actuators with a desired device strain or even actuation shape can be easily fabricated. As shown in the Supplementary Movie 7-9: branched-, circular- and star-shape actuators have been successfully fabricated and demonstrated. Furthermore, it has been demonstrated that, through packaging the liquid electrolyte into an assembly, self-contained devices that can actuate in dry environments can be achieved. These show the versatile potential of the present material system for use as artificial muscles in micro or soft robotics. However, as an electrochemical actuating material, a limitation of the present $\mathrm{Ni}(\mathrm{OH})_{2} / \mathrm{NiOOH}$ material system is that it requires an alkaline electrolyte environment to operate. Future work can focus on packaging the material with a closed material system that provides the electrolytic environment in a self-contained way. 


\section{Conclusions}

We have demonstrated the electrochemical actuation of electrodeposited $\mathrm{Ni}(\mathrm{OH})_{2} / \mathrm{NiOOH}$ with an intrinsic actuating strain $\left(\varepsilon_{o x}\right)$ of $\sim 0.16 \%$, and developed cantilever-actuators made of $\mathrm{Ni}(\mathrm{OH})_{2} / \mathrm{NiOOH}$ on $\mathrm{Ni}$ which can actuate with a device strain $(D / L)$ as large as $70 \%$, at just $\sim 0.4 \mathrm{~V}$ in $\mathrm{NaOH}$. The actuation mechanism is the redox reaction $\mathrm{Ni}(\mathrm{OH})_{2} \leftrightarrow \mathrm{NiOOH}$ involving volume change. The $\mathrm{Ni}(\mathrm{OH})_{2} / \mathrm{NiOOH}$ layer was found to comprise multiple phases of low-crystallinity $\mathrm{Ni}(\mathrm{OH})_{2}, \mathrm{NiOOH}$, and possibly $\mathrm{NiO}$. The thickness ratios of the $\mathrm{Ni}(\mathrm{OH})_{2} / \mathrm{NiOOH}$ and $\mathrm{Ni}$ layers can be easily varied for control of the device strain, load-bearing capability and work density, and masked electrodeposition of $\mathrm{Ni}(\mathrm{OH})_{2} / \mathrm{NiOOH}$ also allows actuators of various 2-D shapes to be made. The alkaline electrolyte required for the electrochemical actuation can be packaged in an assembly of the actuating material to achieve a device that can actuate in air in a selfcontained way.

\section{References}

1. Madden, J.D.W., et al., Artificial muscle technology: Physical principles and naval prospects. Ieee Journal of Oceanic Engineering, 2004. 29(3): p. 706-728.

2. Wang, Q.-M., et al., Nonlinear piezoelectric behavior of ceramic bending mode actuators under strong electric fields. Journal of Applied Physics, 1999. 86(6): p. 3352-3360.

3. $\quad$ Saito, Y., et al., Lead-free piezoceramics. Nature, 2004. 432(7013): p. 84-87.

4. Jaffe, B., Piezoelectric ceramics. Vol. 3. 2012: Elsevier.

5. Pelrine, R., et al., High-field deformation of elastomeric dielectrics for actuators. Materials Science and Engineering: C, 2000. 11(2): p. 89-100.

6. Brochu, P. and Q. Pei, Advances in Dielectric Elastomers for Actuators and Artificial Muscles. Macromolecular Rapid Communications, 2010. 31(1): p. 10-36.

7. Keplinger, C., et al., Stretchable, transparent, ionic conductors. Science, 2013. 341(6149): p. 984-987.

8. Chen, B., et al., Highly stretchable and transparent ionogels as nonvolatile conductors for dielectric elastomer transducers. ACS applied materials \& interfaces, 2014. 6(10): p. 7840-7845.

9. Chen, B., et al., Stretchable and transparent hydrogels as soft conductors for dielectric elastomer actuators. Journal of Polymer Science Part B: Polymer Physics, 2014. 52(16): p. 1055-1060.

10. Otero, T.F., H.-J. Grande, and J. Rodríguez, Reinterpretation of Polypyrrole Electrochemistry after Consideration of Conformational Relaxation Processes. The Journal of Physical Chemistry B, 1997. 101(19): p. 3688-3697.

11. Madden, J.D., et al., Fast contracting polypyrrole actuators. Synthetic Metals, 2000. 113(1): p. 185-192. 
12. Bay, L., et al., A Conducting Polymer Artificial Muscle with $12 \%$ Linear Strain. Advanced Materials, 2003. 15(4): p. 310-313.

13. Garcia-Cordova, F., et al., Biomimetic polypyrrole based all three-in-one triple layer sensing actuators exchanging cations. Journal of Materials Chemistry, 2011. 21(43): p. 17265-17272.

14. Baughman, R.H., et al., Carbon nanotube actuators. Science, 1999. 284(5418): p. 1340-1344.

15. Mirfakhrai, T., et al., Electrochemical actuation of carbon nanotube yarns. Smart Materials and Structures, 2007. 16(2): p. S243.

16. Foroughi, J., et al., Torsional carbon nanotube artificial muscles. Science, 2011. 334(6055): p. 494-497.

17. Lima, M.D., et al., Electrically, chemically, and photonically powered torsional and tensile actuation of hybrid carbon nanotube yarn muscles. Science, 2012. 338(6109): p. 928-932.

18. Weissmüller, J., et al., Charge-Induced Reversible Strain in a Metal. Science, 2003. 300(5617): p. 312-315.

19. Kramer, D., R.N. Viswanath, and J. Weissmüller, Surface-Stress Induced Macroscopic Bending of Nanoporous Gold Cantilevers. Nano Letters, 2004. 4(5): p. 793-796.

20. Viswanath, R., D. Kramer, and J. Weissmüller, Adsorbate effects on the surface stress-charge response of platinum electrodes. Electrochimica Acta, 2008. 53(6): p. 2757-2767.

21. Jin, H.-J., et al., Nanoporous Au-Pt alloys as large strain electrochemical actuators. Nano letters, 2009. 10(1): p. 187-194.

22. Detsi, E., et al., Enhanced strain in functional nanoporous gold with a dual microscopic length scale structure. Acs Nano, 2012. 6(5): p. 3734-3744.

23. Hakamada, M., S. Matsumura, and M. Mabuchi, Electrochemical actuation of nanoporous Ni in $\mathrm{NaOH}$ solution. Materials Letters, 2012. 70: p. 132-134.

24. Cheng, C. and A.H. Ngan, Reversible Electrochemical Actuation of Metallic Nanohoneycombs Induced by Pseudocapacitive Redox Processes. ACS nano, 2015.

25. Bai, S., Z. Yuan, and F. Gao, Materials Chemistry C. J. Mater. Chem, 2016. 100(4): p. 45-52.

26. Cheng, C., J. Weissmüller, and A.H. Ngan, Fast and Reversible Actuation of Metallic Muscles Composed of Nickel Nanowire-Forest. Advanced Materials, 2016.

27. Hall, D.S., et al. Nickel hydroxides and related materials: a review of their structures, synthesis and properties. in Proc. R. Soc. A. 2015. The Royal Society.

28. Li, Y. and Y.T. Cheng, Studies of metal hydride electrodes using an electrochemical quartz crystal microbalance. Journal of the Electrochemical Society, 1996. 143(1): p. 120-124.

29. Wehrens-Dijksma, M. and P. Notten, Electrochemical Quartz Microbalance characterization of $\mathrm{Ni}(\mathrm{OH})$ 2-based thin film electrodes. Electrochimica Acta, 2006. 51(18): p. 3609-3621.

30. Cheng, Y.-T. and M.W. Verbrugge, The influence of surface mechanics on diffusion induced stresses within spherical nanoparticles. Journal of Applied Physics, 2008. 104(8): p. 083521.

31. Cheng, Y.-T. and M.W. Verbrugge, Evolution of stress within a spherical insertion electrode particle under potentiostatic and galvanostatic operation. Journal of Power Sources, 2009. 190(2): p. 453-460.

32. Mcbreen, J., Nickel Hydroxide, in Handbook of Battery Materials, C. Daniel, Besenhard, J.O., Editor. 2011, Wiley-VCH Verlag: Weinheim, Germany. p. 149.

33. Bode, H., K. Dehmelt, and J. Witte, Zur kenntnis der nickelhydroxidelektrode-I. Über das nickel (II)-hydroxidhydrat. Electrochimica Acta, 1966. 11(8): p. 1079-IN1.

34. Oliva, P., et al., Review of the structure and the electrochemistry of nickel hydroxides and oxyhydroxides. Journal of Power Sources, 1982. 8(2): p. 229-255.

35. Bard, A.J., et al., Electrochemical methods: fundamentals and applications. Vol. 2. 1980: Wiley New York.

36. Srinivasan, V., J.W. Weidner, and J. Newman, Hysteresis during cycling of nickel hydroxide active material. Journal of the Electrochemical Society, 2001. 148(9): p. A969-A980. 
37. Gonsalves, M. and A.R. Hillman, Effect of time scale on redox-driven ion and solvent transfers at nickel hydroxide films in aqueous lithium hydroxide solutions. Journal of electroanalytical Chemistry, 1998. 454(1): p. 183-202.

38. Chang, Y.-H., et al., Electrochemical fabrication of transparent nickel hydroxide nanostructures with tunable superhydrophobicity/superhydrophilicity for $2 D$ microchannels application. Journal of Materials Chemistry A, 2014. 2(6): p. 1985-1990.

39. Biesinger, M.C., et al., X-ray photoelectron spectroscopic chemical state quantification of mixed nickel metal, oxide and hydroxide systems. Surface and Interface Analysis, 2009. 41(4): p. 324332.

40. Payne, B., M. Biesinger, and N. McIntyre, Use of oxygen/nickel ratios in the XPS characterisation of oxide phases on nickel metal and nickel alloy surfaces. Journal of Electron Spectroscopy and Related Phenomena, 2012. 185(5): p. 159-166.

41. Casella, I.G., M.R. Guascito, and M.G. Sannazzaro, Voltammetric and XPS investigations of nickel hydroxide electrochemically dispersed on gold surface electrodes. Journal of Electroanalytical Chemistry, 1999. 462(2): p. 202-210.

42. Tench, D. and L.F. Warren, Electrodeposition of conducting transition metal oxide/hydroxide films from aqueous solution. Journal of The Electrochemical Society, 1983. 130(4): p. 869-872.

43. Zhao, Y., et al., Turbostratic carbon nitride prepared by pyrolysis of melamine. Journal of materials science, 2005. 40(9): p. 2645-2647.

44. Mani, B. and J. de Neufville, Dehydration of chemically and electrochemically impregnated (CI and EI) nickel hydroxide electrodes. Journal of The Electrochemical Society, 1988. 135(4): p. 800-803.

45. Acharya, R., et al., Effect of preparation parameters on electrolytic behaviour of turbostratic nickel hydroxide. Materials chemistry and physics, 2003. 81(1): p. 45-49.

46. Blasini, D.R., et al., Observation of intermediate-range order in a nominally amorphous molecular semiconductor film. Journal of Materials Chemistry, 2007. 17(15): p. 1458-1461.

47. Singh, D., Characteristics and Effects of $\gamma$-NiOOH on Cell Performance and a Method to Quantify It in Nickel Electrodes. Journal of the Electrochemical Society, 1998. 145(1): p. 116120.

48. Haring, P. and R. Kotz, Nanoscale Thickness Changes of Nickel-Hydroxide Films During Electrochemical Oxidation-Reduction Monitored by in-Situ Atomic-Force Microscopy. Journal of Electroanalytical Chemistry, 1995. 385(2): p. 273-277.

49. $\mathrm{Hu}, \mathrm{Y}$. and D.A. Scherson, Potential-induced plastic deformations of nickel hydrous electrodes in alkaline electrolytes: An in situ atomic force microscopy study. The Journal of Physical Chemistry B, 1997. 101(27): p. 5370-5376.

\section{Acknowledgements}

The work was funded by a grant from the Research Grants Council (Project No. 17206114) of the Hong Kong Special Administrative Region, as well as the Kingboard Endowed Professorship in Materials Engineering. We thank F.Y.F. Chan for help with TEM sample preparation, D.Y.K. Mak and R.K.M. Ho for help with TEM operation and N.K.C. Ho for help with XPS operation. 

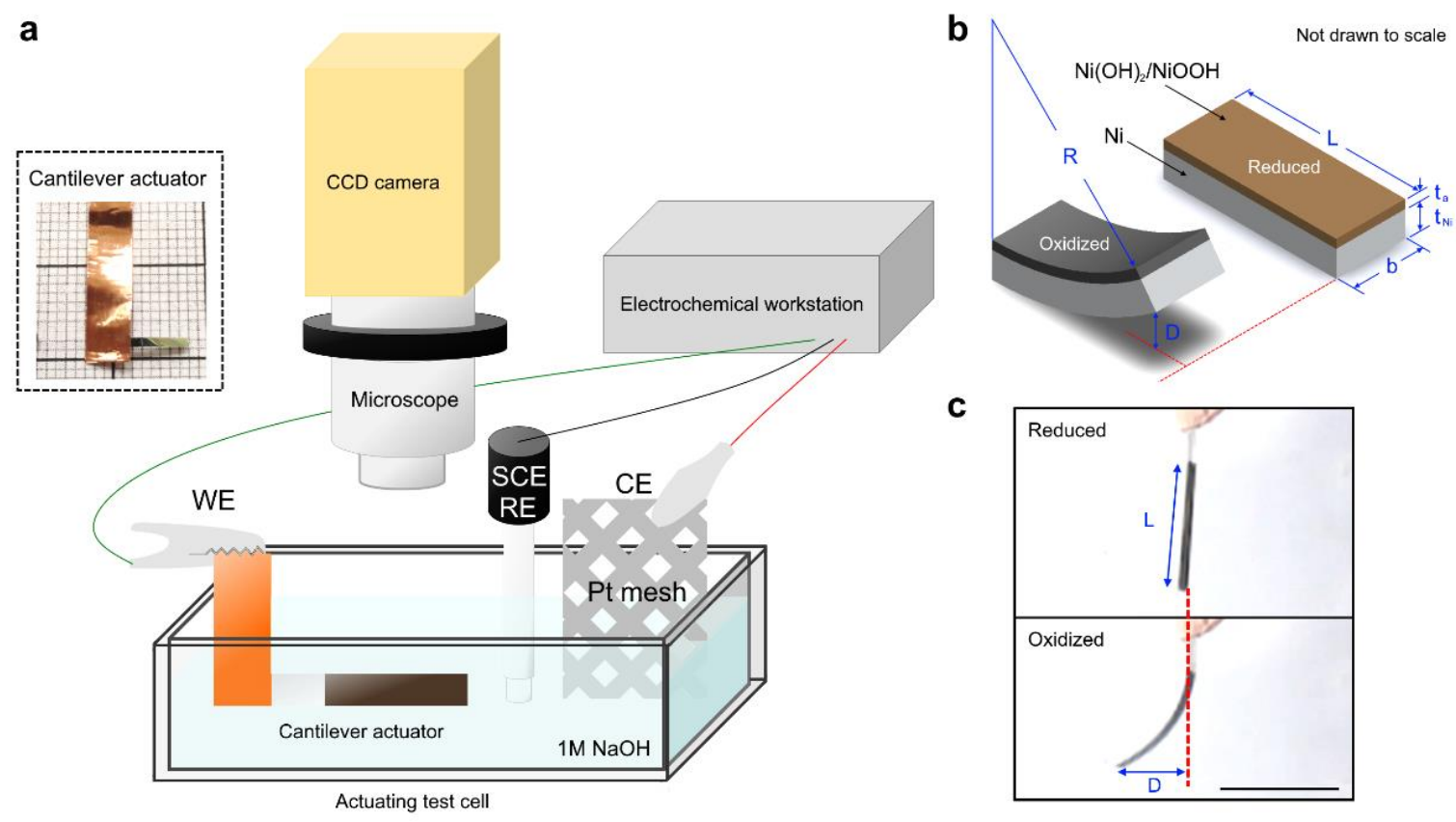

Figure 1 Actuators and actuation test cell. a. Schematic showing the actuation testing system. The working electrode (WE), counter electrode (CE) and reference electrode (RE) of the electrochemical workstation are connected to the cantilever actuator, platinum mesh and standard calomel electrode respectively. The end-deflection of the actuator is video-recorded by a CCD camera through a microscope or directly by a compact digital camera. Inset shows photograph of a real, typical cantilever-actuator against a background grid of $1 \mathrm{~mm}$ grid spacing. b. Schematic diagram of cantilever-actuator. c. Photographs captured from a cantilever-actuator when being reduced and oxidized during an actuation test (Scale bar: 5 $\mathrm{mm})$. 

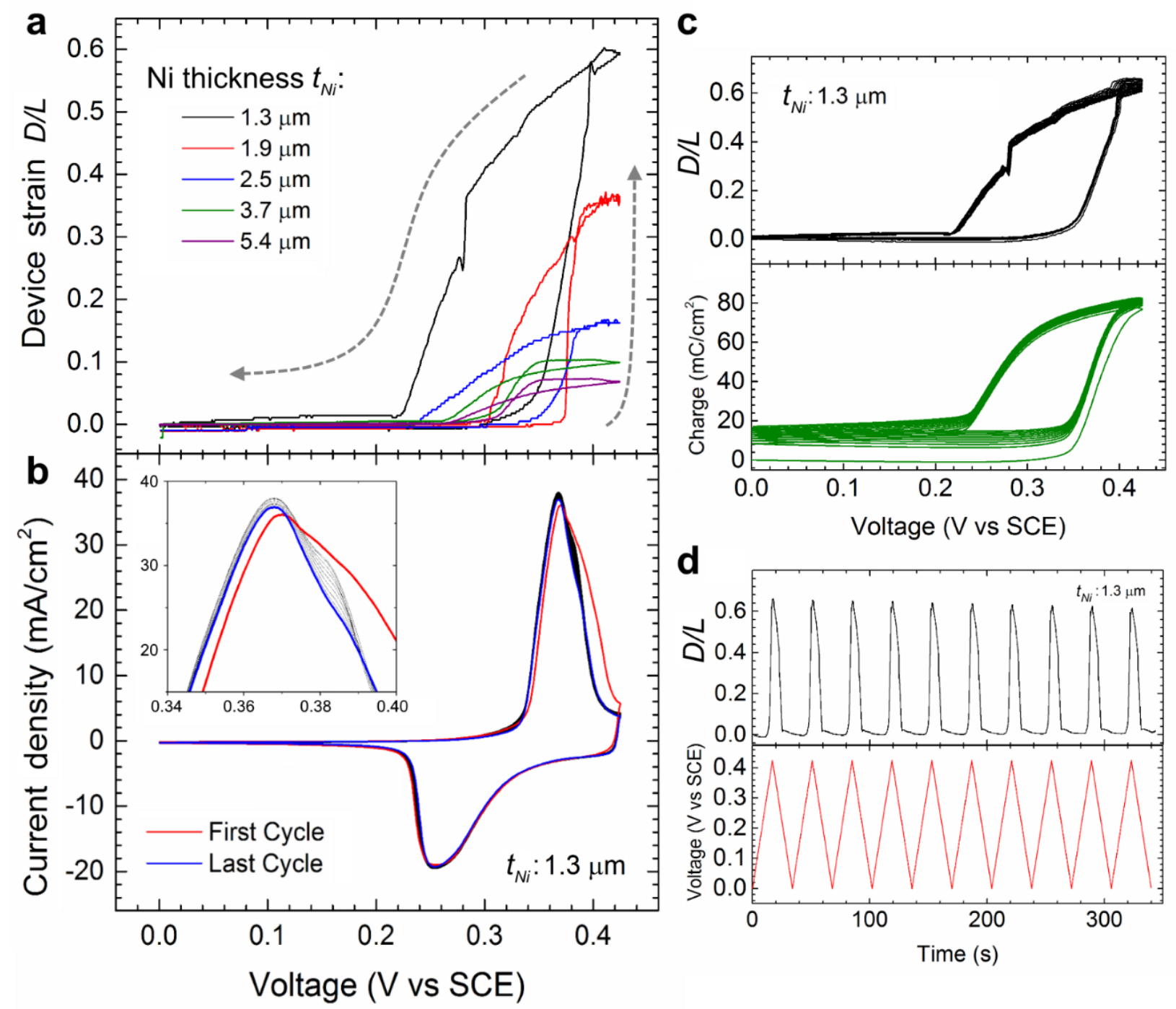

Figure 2 Cyclic actuation test results. a. Device strain $D / L$ of the cantilever-actuator of different $\mathrm{Ni}$ thickness $t_{N i}$ against the voltage applied. b. The corresponding of cyclic voltammetry of $t_{N i}=1.3 \mu \mathrm{m}$. c. $D / L$ of, and charge transferred across, the cantilever-actuator of $t_{N i}=1.3 \mu \mathrm{m}$. d, $D / L$ and the applied voltage against time. The actuation was tested in CV of $0-0.425 \mathrm{~V}$ vs SCE and $25 \mathrm{mV} / \mathrm{s}$, under $1 \mathrm{M} \mathrm{NaOH}$. 

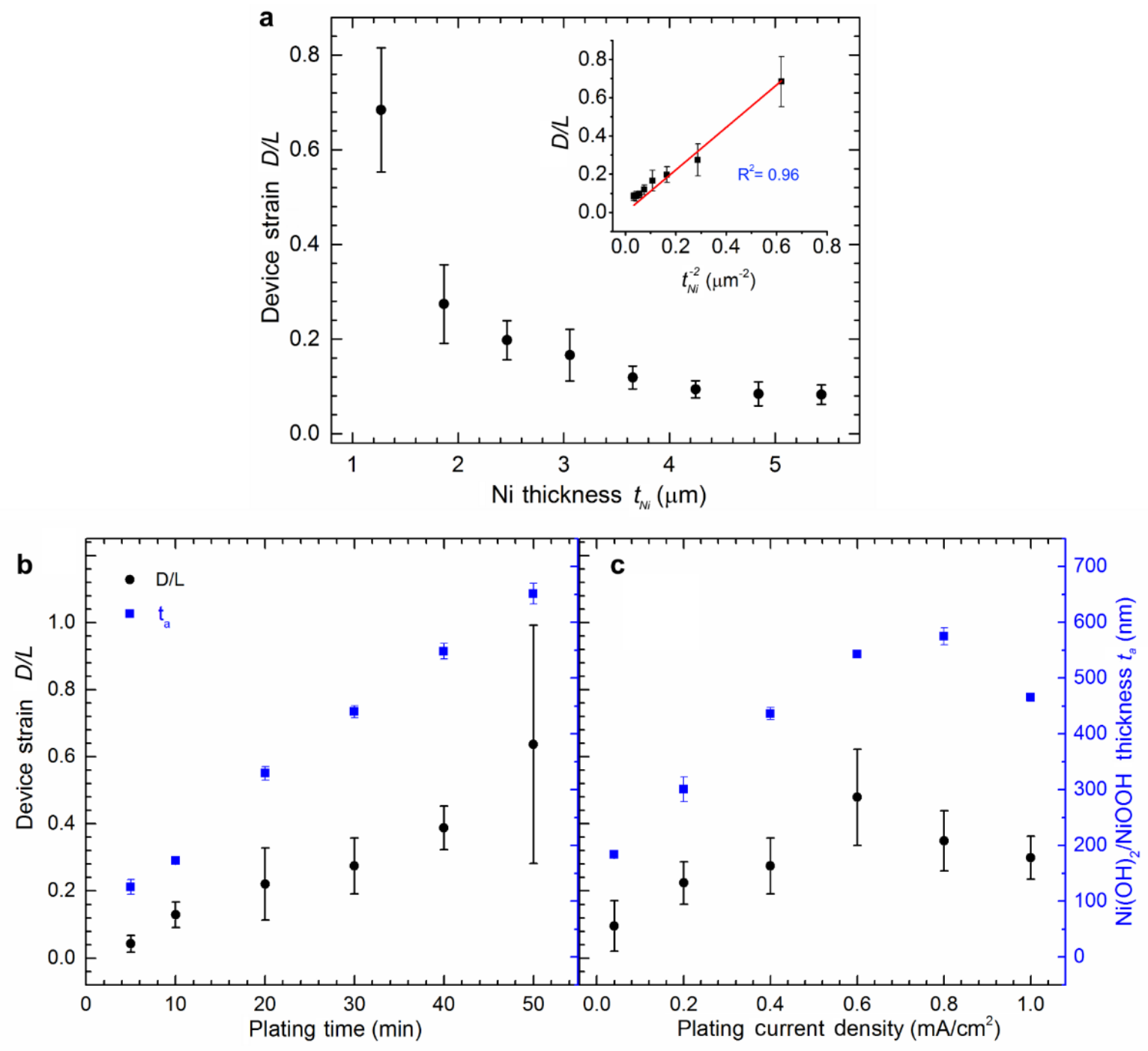

d
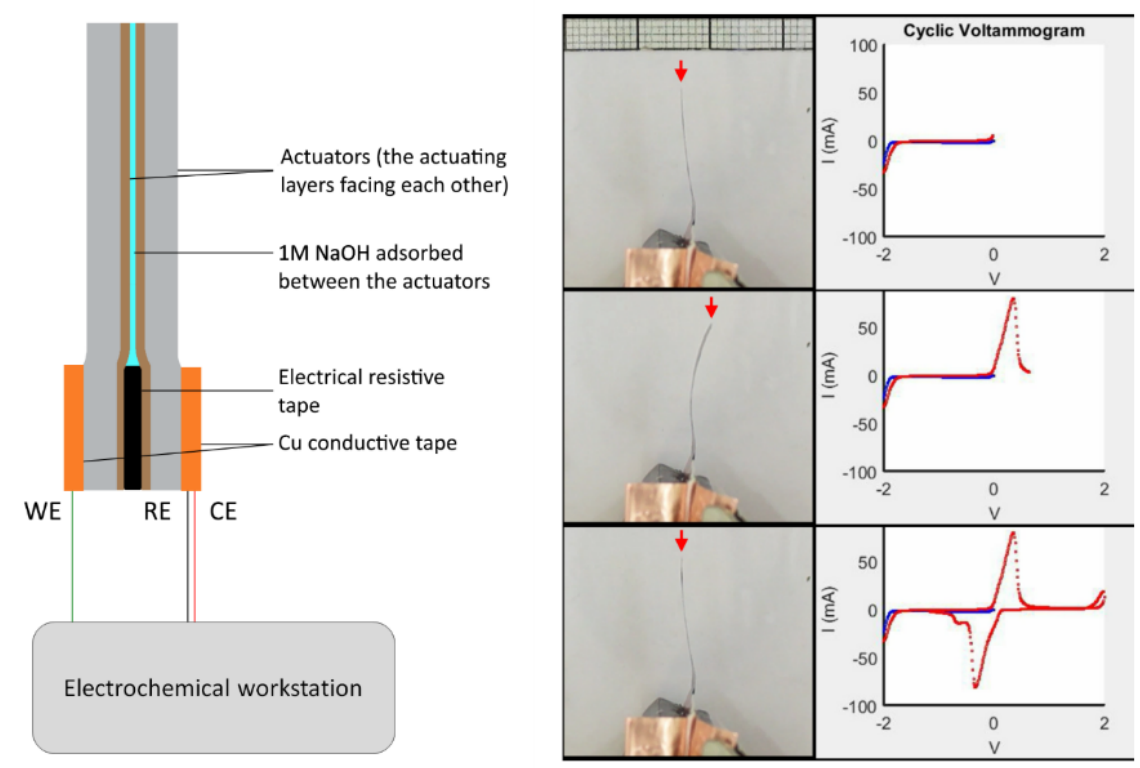
Figure 3 Device performance under different fabrication conditions. a. Measured peak device strain $D / L$ of cantilever-actuators in $1 \mathrm{M} \mathrm{NaOH}$ vs their $\mathrm{Ni}$ thickness $t_{N i}$, with the $\mathrm{Ni}(\mathrm{OH})_{2} / \mathrm{NiOOH}$ layers deposited at $0.4 \mathrm{~mA} / \mathrm{cm}^{2}$ for $30 \mathrm{~min}$ in all cases. b,c. Effects of plating time (b) and current density (c) on the thickness of $\mathrm{Ni}(\mathrm{OH})_{2} / \mathrm{NiOOH} t_{a}$ and device strain $D / L$, with $t_{N i}=1.9 \mu \mathrm{m}$. The plating current density for $\mathbf{b}$ was $0.4 \mathrm{~mA} / \mathrm{cm}^{2}$, and the plating time for $\mathbf{c}$ was $30 \mathrm{~min}$. (Number of data measurement $\mathrm{n}=50$ for $D / L$, $\mathrm{n}=10$ for $t_{a}$. Error bars: standard deviation) d. Self-contained actuating assembly - (left) schematic showing construction and (right) snapshots (from Supplementary Movie 3) showing actuation in air and the corresponding cyclic voltammogram under cyclic voltage scan rate of $1 \mathrm{~V} / \mathrm{s}$ from $-2 \mathrm{~V}$ to $+2 \mathrm{~V}$. 

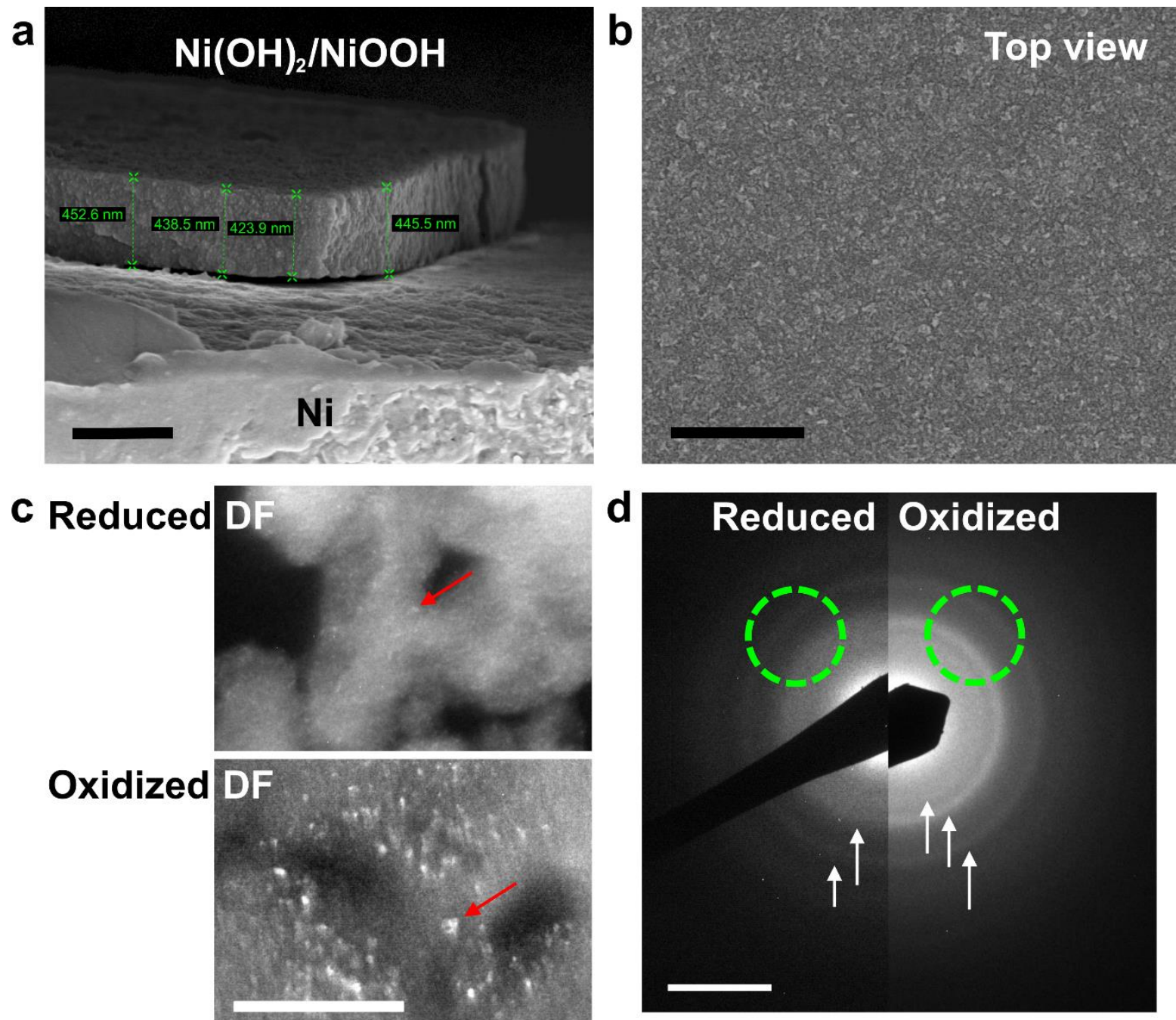

Figure 4 Electron microscopy. a-b. SEM images of the electrodeposited $\mathrm{Ni}(\mathrm{OH})_{2} / \mathrm{NiOOH}$ : cross section (a) and top view (b) (scale bar: $50 \mathrm{~nm}$ ). c. TEM dark-field (DF) images of the reduced and oxidized $\mathrm{Ni}(\mathrm{OH})_{2} / \mathrm{NiOOH}$ taken using the portions of the diffraction patterns encircled in $\mathbf{d}$ (common scale bar: 100 nm). Nano-crystals shown up as bright spots are indicated by red arrows. d. Selected area electron diffraction patterns of the reduced and oxidized $\mathrm{Ni}(\mathrm{OH})_{2} / \mathrm{NiOOH}\left(\right.$ common scale bar: $\left.5 \mathrm{~nm}^{-1}\right)$. The dashed circles indicate the positions of the objective aperture when the DF images in c were taken. The bright nanocrystals in $\mathbf{c}$ therefore have crystal structures corresponding to the diffraction rings inside the circles (indicated by arrows). 

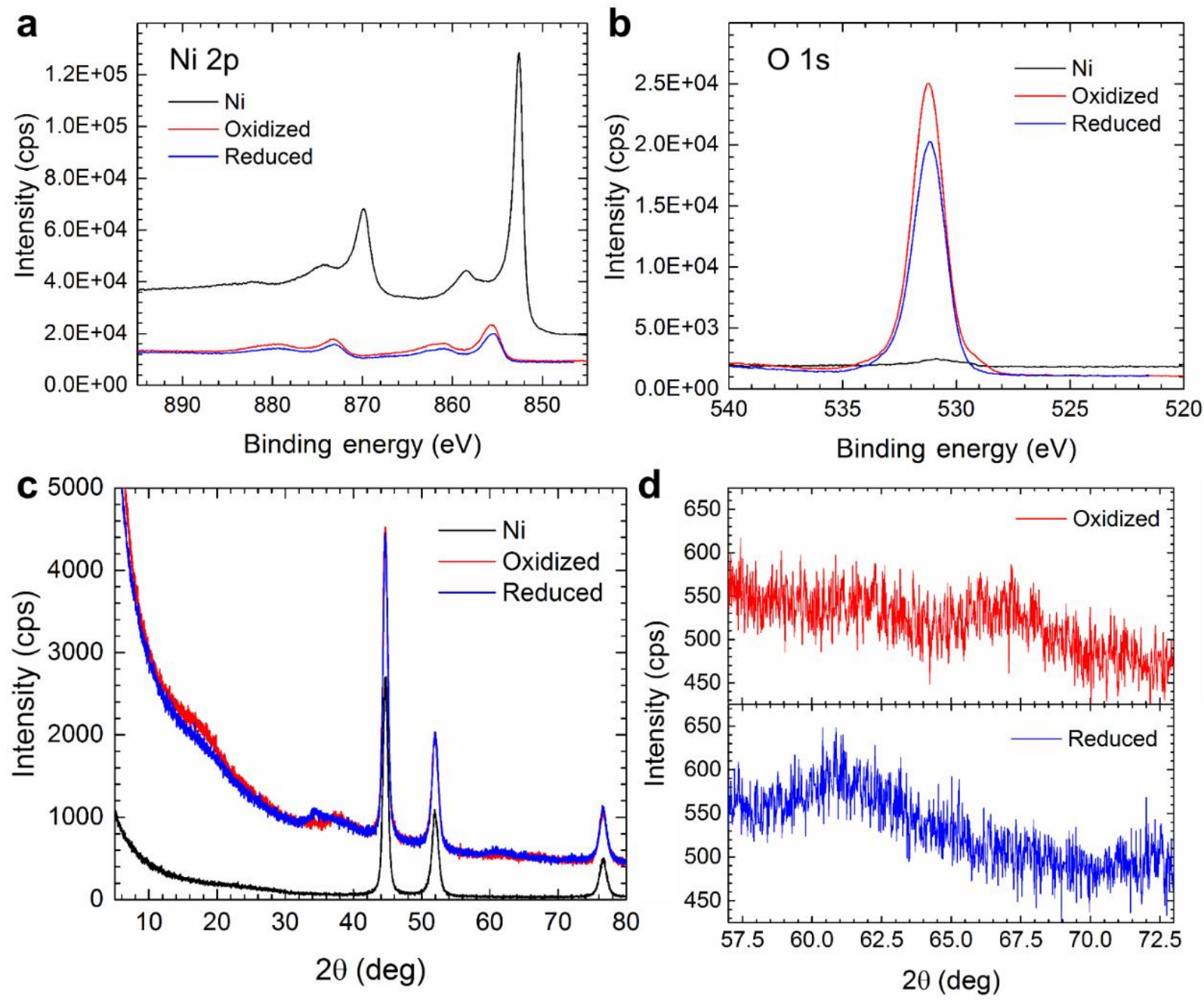

Figure 5 X-ray Characterization. a-c. Ni 2p (a) and O 1s (b) XPS spectra and grazing incidence XRD (c) for $\mathrm{Ni}$ and oxidized and reduced $\mathrm{Ni}(\mathrm{OH})_{2} / \mathrm{NiOOH}$. d. Enlarged views of the last $\mathrm{XRD}$ peaks for oxidized and reduced $\mathrm{Ni}(\mathrm{OH})_{2} / \mathrm{NiOOH}$. 
Table 1 The matching of inter-planar spacing measured by SAED and XRD. NiO (JCPDS cards No. 040835), $\alpha / \beta-\mathrm{Ni}(\mathrm{OH})_{2}$ [27], $\gamma / \beta-\mathrm{NiOOH}(\mathrm{JCPDS}$ cards No. 06-0075) [47].

\begin{tabular}{|c|c|c|c|c|c|c|}
\hline \multicolumn{3}{|c|}{ Inter-planar spacing measured by SAED $(\AA)$} & \multicolumn{4}{|c|}{ Inter-planar spacing measured by XRD $(\AA)$} \\
\hline \multirow[t]{2}{*}{ Oxidized } & \multirow[t]{2}{*}{ Reduced } & & \multicolumn{2}{|r|}{ Oxidized } & \multicolumn{2}{|r|}{ Reduced } \\
\hline & & & 4.93 & / & 5.37 & / \\
\hline 2.50 & I & $(111) \alpha-\mathrm{Ni}(\mathrm{OH})_{2}$ & 2.34 & (102) $\gamma-\mathrm{NiOOH}$ & 2.56 & $(111) \alpha-\mathrm{Ni}(\mathrm{OH})_{2}$ \\
\hline \multirow{2}{*}{2.10} & \multirow{2}{*}{2.09} & $(200) \mathrm{NiO}$ & & & & \\
\hline & & (105) $\gamma-\mathrm{NiOOH}$ & & & & \\
\hline \multirow{4}{*}{1.48} & \multirow{4}{*}{1.47} & $(220) \mathrm{NiO}$ & \multirow{4}{*}{1.39} & \multirow{2}{*}{ (110) $\gamma-\mathrm{NiOOH}$} & \multirow{4}{*}{1.52} & \multirow{4}{*}{ (301) $\alpha-\mathrm{Ni}(\mathrm{OH})_{2}$} \\
\hline & & $(301) \alpha-\mathrm{Ni}(\mathrm{OH})_{2}$ & & & & \\
\hline & & $(111) \beta-\mathrm{Ni}(\mathrm{OH})_{2}$ & & \multirow{2}{*}{ (110) $\beta-\mathrm{NiOOH}$} & & \\
\hline & & $(00,14) \gamma-\mathrm{NiOOH}$ & & & & \\
\hline
\end{tabular}

